\title{
Commentary: Saphenous vein graft risk score: But where is the vein?
}

\author{
Bobby Yanagawa, MD, PhD, ${ }^{\mathrm{a}}$ and Mario F. L. Gaudino, $\mathrm{MD}^{\mathrm{b}}$ \\ From the a Division of Cardiac Surgery, St Michael's Hospital, University of Toronto, Toronto, Ontario, Canada; \\ and ${ }^{\mathrm{b}}$ Department of Cardiothoracic Surgery, Weill Cornell Medical College, New York, NY. \\ Disclosures: Authors have nothing to disclose with regard to commercial support. \\ Received for publication July 15, 2019; accepted for publication July 17, 2019; available ahead of print July 25, \\ 2019. \\ Address for reprints: Mario F. L. Gaudino, MD, Cardiothoracic Surgery at Weill Cornell Medical Center, 525 East \\ 68th St, M-404, New York, NY 10065 (E-mail: mfg9004@med.cornell.edu). \\ J Thorac Cardiovasc Surg 2020;160:128-9 \\ $0022-5223 / \$ 36.00$ \\ Copyright $₫ 2019$ by The American Association for Thoracic Surgery \\ https://doi.org/10.1016/j.jtcvs.2019.07.031
}

Antonopoulos and colleagues ${ }^{1}$ performed an individual patient data (IPD) meta-analysis to form a virtual database then developed a risk model for early saphenous vein graft (SVG) failure after coronary artery bypass graft (CABG). The aggregate meta-analysis of 48 studies including 41,530 grafts reported an $11 \%$ rate of early SVG failure. The authors then used IPD from a consortium of 8 collaborating centers enrolling 1864 patients to establish an SVG failure risk model. Age, sex, body mass, dyslipidemia, diabetes, smoking creatinine levels, on-pump surgery, endoscopic harvesting, complex grafting, target vessel, and number of vein grafts were independent predictors of SVG occlusion during the first year. The authors suggest that such a risk model could be used to guide the use of medications-dual antiplatelet therapy (DAPT) and optimal cholesterol-lowering medications-for optimal vein graft performance.

We applaud the authors for their efforts to optimize the outcomes of standard CABG-performed with the use of single internal thoracic artery and veins. The use of data from an IPD meta-analysis to produce a database from which to establish a risk score is innovative and novel.

As with any meta-analysis, the quality of the outcomes will depend on the quality of the individual studies. Here, the studies in the aggregate meta-analysis had incomplete angiographic follow-up, and not all studies had protocolized angiograms (or computed tomography angiograms). In other words, in some studies angiograms were based on clinical need, such as evidence of acute myocardial infarction, and as such graft occlusion events may be overestimated. Overall, differences in study protocols may have contributed to the high heterogeneity reported in these data.

In vein grafts, as in all aspects of surgery, the devil is in the details. This study did not address how the vein looked, how it was harvest and prepared, or how it was used. We know that SVGs, like rivers, are not all made the same (Figure 1). Some veins are beautiful, straight segments.

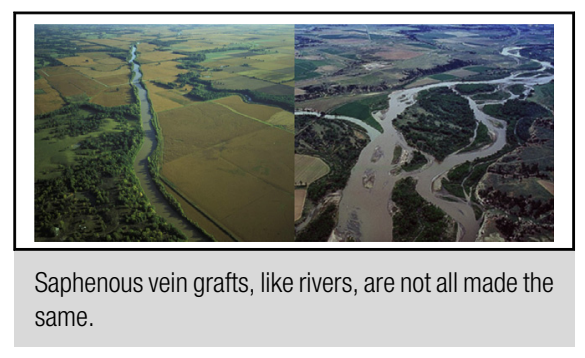

Central Message

It is unlikely that a risk score could be used to guide grafting strategy.

See Article page 116

Yet others are aneurysmal, have twists and turns with branches, valves and caliber changes throughout. There is no formal scoring system for vein quality, but we intuitively know that the former has a better chance of staying patent compared with the latter. With regards to vein harvest, endoscopic versus open versus no-touch harvest, highpressure distension versus not, use of various storage solutions, copious irrigation for removal of all luminal clots, etc- these factors can all affect vein graft performance. ${ }^{2-5}$ In this study, endoscopic harvest was associated with early graft failure, a result that was supported by a recent systematic review and meta-analysis. ${ }^{6}$ Finally, there are surgeons who routinely use 3 to 4 grafts to large targets with sizable perfusion beds and there are surgeons who routinely use 7 to 8 grafts, many to smaller secondary obtuse marginal, acute marginal, or diagonal targets. To this point, risk factors for graft failure included number of grafts and location (eg, greater failure in the diagonal position). Indeed, graft occlusion in a smaller distal territory may be clinically silent with no significant sequelae as long as grafts to the major territories remain patent.

Given that SVGs are still the most common bypass conduit used, initiatives to better understand early failure are important. The rationale for a risk score, however, is a little unclear. If there is evidence for a protective role of DAPT for early vein graft patency, then we should use this for all patients. Our patients with acute coronary syndrome who undergo CABG are already on DAPT for 1 year routinely based on our practice guidelines. The same is true for optimal cholesterol-lowering therapy with a combination of statin and PCSK9 inhibitors. To this point, medical optimization 


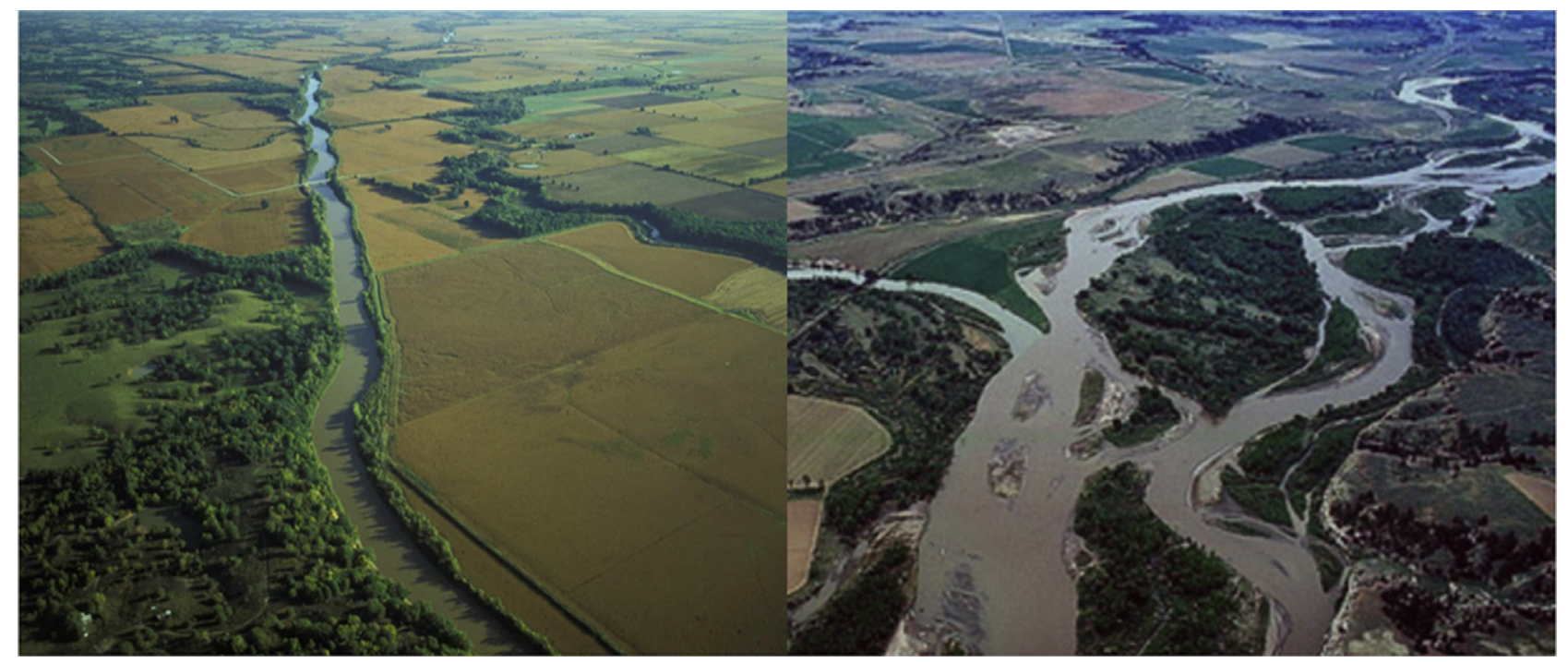

FIGURE 1. Saphenous vein grafts, like rivers, are not all made the same.

of patients after CABG is a clinically unmet need. Review of the Future Revascularization Evaluation in Patients with Diabetes Mellitus: Optimal Management of Multivessel Disease (FREEDOM) Trial supplementary data revealed that in this closely monitored post-CABG cohort at 1 year, only $89.2 \%$ of patients were on a statin, $82.2 \%$ were on a betablocker, and $70.0 \%$ were on an angiotensin-converting enzyme inhibitor. ${ }^{8}$ The same can be said for tight glycemic control and smoking cessation, which should be a priority post-CABG. Finally, could a risk score be used to determine which patients are at risk of early vein graft failure and thus who should have multiple arterial grafting? There are strong data to show that most patients will benefit from use of a second arterial graft and, to our knowledge, there are no data showing a downside to such a strategy. ${ }^{9}$ The primary determinant for use or non-use of multiple arterial grafting is based mainly on surgeon or institutional expertise and preference. Therefore, it is unlikely that a risk score could be used to guide grafting strategy.

\section{References}

1. Antonopoulos AS, Odutayo A, Oikonomou EK, Trivella M, Petrou M, Collins GS, et al; SAFINOUS-CABG (SAphenous vein graft Fallure-AN OUtcomes Study in Coronary Artery Bypass Grafting) group. Development of a risk score for early saphenous vein graft failure: an individual patient data meta-analysis. $J$ Thorac Cardiovasc Surg. 2020;160:116-27.e4.

2. Samano N, Geijer H, Liden M, Fremes S, Bodin L, Souza D. The no-touch saphenous vein for coronary artery bypass grafting maintains a patency, after 16 years, comparable to the left internal thoracic artery: a randomized trial. J Thorac Cardiovasc Surg. 2015;150:880-8.

3. Deb S, Singh SK, de Souza D, Chu MWA, Whitlock R, Meyer SR, et al SUPERIOR SVG: no touch saphenous harvesting to improve patency following coronary bypass grafting (a multi-centre randomized control trial, NCT01047449). J Cardiothorac Surg. 2019;14:85.

4. Dashwood MR, Savage K, Tsui JC, Dooley A, Shaw SG, Fernández Alfonso MS, et al. Retaining perivascular tissue of human saphenous vein grafts protects against surgical and distension-induced damage and preserves endothelial nitric oxide synthase and nitric oxidesynthase activity. J Thorac Cardiovasc Surg. 2009;138: 334-40.

5. Souza DS, Dashwood MR, Tsui JC, Filbey D, Bodin L, Johansson B, et al Improved patency in vein grafts harvested with surrounding tissue: results of a randomized study using three harvesting techniques. Ann Thorac Surg. 2002;73: 1189-95.

6. Kodia K, Patel S, Weber MP, Luc JGY, Choi JH, Maynes EJ, et al. Graft patency after open versus endoscopic saphenous vein harvest in coronary artery bypass grafting surgery: a systematic review and meta-analysis. Ann Cardiothorac Surg. 2018;7:586-97.

7. Cardoso R, Knijnik L, Whelton SP, Rivera M, Gluckman TJ, Metkus TS, et al Dual versus single antiplatelet therapy after coronary artery bypass graft surgery: an updated meta-analysis. Int J Cardiol. 2018;269:80-8.

8. Farkouh ME, Domanski M, Sleeper LA, et al. Strategies for multivessel revascularization in patients with diabetes. $N$ Engl J Med. 2012;367:2375-84.

9. Gaudino MFL, Spadaccio C, Taggart DP. State-of-the-art coronary artery bypass grafting: patient selection, graft selection, and optimizing outcomes. Interv Cardiol Clin. 2019;8:173-98. 